\title{
Analytical Approach for Optimal Allocation of Distributed Generators to Minimize Losses
}

\author{
Navdeep Kaur ${ }^{\dagger}$ and Sanjay Kumar Jain*
}

\begin{abstract}
In this paper the integration of Distributed Generation (DG) in radial distribution system is investigated by computing the optimal site and size of DG to be placed. An analytical expression based on equivalent current injection has been derived by utilizing topological structure of radial distribution system to find optimal size of DG to minimize losses. In the presented formulation, the optimal DG placement is obtained without repeatedly computing the load flow. The proposed formulation can be used to find the optimal size of all types of DGs namely Type-I, Type-II, Type-III and Type-IV DGs. The investigations are carried out on IEEE 33-bus and 69-bus radial distribution systems. The optimal DG placement results into reduction in active and reactive power losses and improvement in voltage profile of the buses.
\end{abstract}

Keywords: Distributed generation, Optimal site and size, Loss reduction, Equivalent current injection, Voltage profile improvement

\section{Introduction}

In conventional radial distribution system, the generation is central where power is transferred from generating station to load centers. These systems are characterized by high losses and high $\mathrm{R} / \mathrm{X}$ ratio. The voltages of buses also decrease when moved away from generating station. Further, the load demand is also increasing day by day and the system should be able to supply the increased load demand.

Nowadays, there is motivation to harness renewable resources and add even small capacity generation. These small capacity generators are regarded as Distributed generation (DG) or Dispersed generation. The usage of DGs is directed to reduce power losses and meet the load demand.

The loss reduction at distribution level is interesting challenge to researches. The capacitor placement and reconfiguration are also used to reduce distribution losses. The integration of DG benefits the distribution system by reducing the losses, improving bus voltages and improving the reliability of the distribution system. The usage of DGs will be advantageous only if the capacity and locations are selected optimally. The DGs can be based on fuel cells, photovoltaic system, wind turbines, mini/micro hydro turbines, gas turbines and micro turbines. Akorede et al. [1] and Jiayi et al. [2] reviewed distribution energy resources and distributed generation technologies. The DGs can be categorized in four Types [3] on the basis of their terminal

$\dagger$ Corresponding Author: Dept. of Electrical and Instrumentation Engineering, Thapar University Patiala, India.

(navdeep.kaur@thapar.edu)

* Dept. of Electrical and Instrumentation Engineering, Thapar

University Patiala, India. (skjain@thapar.edu)

Received: August 22, 2016; Accepted: May 23, 2016 characteristics as:

1. Type-I DGs are based on fuel cells, photovoltaic systems and supplies active power only.

2. Type-II DGs can be synchronous compensator, capacitors etc. and supplies reactive power only.

3. Type-III DGs supply both active and reactive power and are based on synchronous machines.

4. Type-IV DGs supply real power but absorb reactive power such as induction generators driven by wind turbines.

Various techniques are reported in literature for solving problem of optimal allocation of Distributed Generators. The different objective functions are dealt for such optimization but loss minimization is most widely opted objective. ElKhattam et al. [4] proposed heuristic approach for planning of DG capacity to maximize benefits to distribution companies. Carpinelli et al. [5] developed an $\varepsilon$-constrained technique to suggest allocation of dispersed generation in presence of uncertainties to minimize cost of energy losses, voltage profile and total harmonic distortion. An algorithm using combinational GA and $\varepsilon$-constrained technique is proposed by Celli et al. [6] to determine location and size of distributed generators by minimizing different functions related to cost of energy losses, cost of service interruptions, cost of network upgrading and cost of energy purchased. Tabu search based algorithm is used by Golshan and Arefifar [7] to find optimal size and site of DG sources and reactive power sources by minimizing cost of power and energy losses. Combination of genetic algorithm and optimal power flow is employed by Harrison et al. [8] to optimally site and size predefined number of DGs. Moradi and Abedini [9] presented the heuristic by combining features of genetic algorithm and particle swarm optimization 
(PSO) to optimally site and size DG for minimization of losses and better voltage regulation. Optimal size and site of DG to minimize power losses is found by Dasan and Devi [10] using fuzzy adaptation of evolutionary algorithm. Genetic Algorithm is used by Shukla et al. [11] for appropriate allocation and sizing of DG in distribution system by minimizing losses. A new population based methodology is proposed by Singh and Goswami [12] for optimal placement of DG to maximize profit and reduction in losses. Optimal sizing and siting of DG is done by Ant bee colony Algorithm by Abu-mouti and El-Hawary [13] to reduce the system losses. Khalesi et al. [14] used dynamic programming for loss reduction and enhancement of reliability of system by optimal siting and sizing DG. Acharya et al. [15] used analytical expressions based on exact loss formula to find optimal location and size of DG. Optimal size, site and power factor of Type-III DG is obtained by Hung et al. [3] by developing analytical expressions based on exact loss formula to minimize losses. Gözel and Hocaoglu [16] employed equivalent current injection based sensitivity factor to optimally site and size in distribution system to minimize power losses. Reduction in losses and enhancement in loadability is done by Hung and Mithulananthan [17] by placing DG of optimal size and power factor at optimal site by using analytical approach. Sequential quadratic programming is applied by Darfoun and El-Hawary [18] to find optimal size and place of DG to minimize losses and installation cost of DG. Kayal and Chanda obtained [19] optimal size and site of solar and wind based DGs by employing PSO to minimize losses in distribution system and to improve voltage stability. Shuffled frog leaping algorithm is used by Yammani et al. [20] to optimally site and size DG in distribution system for minimizing real power losses and cost of DG. Kansal et al. [21] obtained the optimal site and size of three types of DG i.e. Type-I, Type-II and Type-III DG for loss minimization by using PSO. In [3] and [15] optimal placement of DG is done by analytical expressions which requires formulation of bus impedance matrix. Due to characteristics and complexity and size of distribution system this method is not applicable to distribution systems directly [16].

From the literature review, it is observed that most of the research works on optimal placement of DG accounts only the Type-I DG. In this proposed work the placement of all four types of DG are considered. The optimal placement is attempted by deriving analytical expressions based on equivalent current injection for loss minimization. The presented formulation utilizes the topological characteristics of the radial distribution system and does not require to repeatedly calculate load flow. The analytical expression is derived for the placement of Type-I, Type-II, Type-III and Type-IV DGs. Optimal placement problem is solved for IEEE-33 bus and 69-bus radial distribution system.

\section{Optimal Allocation of DGs}

The presented analytical approach for optimal allocation of DG is based on loss minimization. This analytical formulation is based on equivalent current injection method that exploits the topological structure of radial distribution system. The formulation utilizes Bus injection to branch current (BIBC) and Branch current to Bus voltage (BCBV) matrices whose formulation can be found in [22].

\subsection{The objective}

The optimum size and site of DGs are determined for minimizing total power loss $P_{\text {loss }}$. The total power loss is formulated as a function of the power injections based on the equivalent current injection [16]. The power loss $P_{\text {loss }}$, which is the objective to be minimized, is expressed as -

$$
\begin{aligned}
& P_{\text {loss }}=[R]^{T}\left([B I B C]\left[\frac{P \cos (\theta)+Q \sin (\theta)}{|V|}\right]\right)^{2}+ \\
& {[R]^{T}\left([B I B C]\left[\frac{P \sin (\theta)-Q \cos (\theta)}{|V|}\right]\right)^{2}}
\end{aligned}
$$

The Eq. (1) can be re-written into expanded form as -

$$
\begin{gathered}
\frac{\partial \text { Ploss }}{\partial P_{i}}=\sum_{i=1}^{n b} 2 R_{j}\left(\sum_{j=2}^{n} B I B C_{i, j-1}\left[\frac{P_{j} \cos \left(\theta_{j}\right)+Q_{j} \sin \left(\theta_{j}\right)}{\left|V_{j}\right|}\right]\right)^{2} \\
+\sum_{i=1}^{n b} R_{i}\left(\sum_{j=2}^{n} B I B C_{i, j-1}\left[\frac{P_{j} \cos \left(\theta_{j}\right)-Q_{j} \sin \left(\theta_{j}\right)}{\left|V_{j}\right|}\right]\right)^{2}
\end{gathered}
$$

where,

$n$ is total number of buses;

$n b$ is total number of branches in system;

$B I B C$ is bus-injection to bus-current matrix;

$P_{j}$ is active power injection at $j^{\text {th }}$ bus and

$Q_{j}$ is reactive power injection $j^{\text {th }}$ bus.

\subsection{Sizing of DG}

The optimal size of all four types of DG at each bus is obtained by expressing the reactive power output of DG, $Q_{D G}$, in terms of its active power output $P_{D G}$ as -

$$
Q_{D G}=a P_{D G}
$$

where, $a=(\operatorname{sign}) \tan \left(\cos ^{-1}\left(P F_{D G}\right)\right)$

The sign value is taken as +1 for Type-III DG and -1 for Type-IV DG. $P F_{D G}$ is the power factor of DG. 
The optimal power factor of DG for minimum loss is equal to power factor of load [3]. It is expressed as:

$$
P F_{D G}=P F_{D}=\frac{\sum_{i=1}^{n} P_{D i}}{\sqrt{\left(\sum_{i=1}^{n} P_{D i}\right)^{2}+\left(\sum_{i=1}^{n} Q_{D i}\right)^{2}}}
$$

where $P_{D i}$ is active power load demand and $Q_{D i}$ is reactive power load demand at $i^{\text {th }}$ bus. Combining (2) and (3) active power loss can be written as:

$$
\begin{aligned}
& P_{\text {loss }}=\sum_{i=1}^{n b} R_{i}\left(\sum_{j=2}^{n} B I B C_{i, j-1}\left[\frac{P_{j} \cos \left(\theta_{j}\right)+a P_{j} \sin \left(\theta_{j}\right)}{\left|V_{j}\right|}\right]\right)^{2} \\
& +\left(\sum_{j=2}^{n} B I B C_{i, j-1}\left[\frac{P_{j} \cos \left(\theta_{j}\right)-a P_{j} \sin \left(\theta_{j}\right)}{\left|V_{j}\right|}\right]\right)^{2}
\end{aligned}
$$

The objective to find the optimum size of DG at a bus is calculated by making the power loss to real power injection sensitivity factor as zero i.e. $\frac{\partial P l o s s}{\partial P_{k}}=0$. This has the consideration that the total power loss will be minimum if the partial derivative of total power loss w.r.t. injected real power becomes zero. With the consideration of $\frac{\partial P \text { loss }}{\partial P_{k}}=0$ from (5), the optimal size of injected power at $k^{\text {th }}$ bus can be expressed as:

$$
P_{k}=-\frac{\left|V_{k}\right| \sum_{i=1}^{n b} R_{i} \sum_{\substack{j=2 \\ j \neq k}}^{n} d P B I B C_{k(i . j-1)}\left[\operatorname{Re}\left(I_{j}\right)+\operatorname{Im}\left(I_{j}\right)\right]}{\left(1+a^{2}\right) \sum_{i=1}^{n b} R_{i} d P B I B C_{k(i, j-1)}}
$$

where,

$$
\begin{aligned}
& \operatorname{Re}\left(I_{j}\right)=\left(\cos \theta_{k}+a \sin \theta_{k}\right) \cdot r e\left(I_{j}\right) \\
& \operatorname{Im}\left(I_{j}\right)=\left(\sin \theta_{k}-a \cos \theta_{k}\right) \cdot \operatorname{im}\left(I_{j}\right)
\end{aligned}
$$

The negative sign in above equation indicates that $P_{k}$ should be injected to system. The matrix $d B I B C$ can be obtain by simple algorithm given in [16]. The detailed mathematical derivation of Eq. (6) is given in Appendix A. With this, the optimal size of DG can be obtained as:

$$
P_{d g k}=P_{k}+P_{l o a d k}
$$

The reactive $Q_{d g k}$ power is therefore can be obtained as -

$$
\begin{aligned}
Q_{k} & =a P_{k} \\
Q_{d g k} & =Q_{k}+Q_{\text {loadk }}
\end{aligned}
$$

The optimal power factor depends on type of DG. The optimal size for each type of DG can be obtained as:

Type-I DG: For Type-I DG, power factor is unity, $\mathrm{a}=0$. Combining Eq. (6) and Eq. (7) yields $P_{d g k}$ as -

$$
P_{d g k}=\frac{\left|V_{k}\right| \sum_{i=1}^{n b} R_{i} \sum_{\substack{j=2 \\ j \neq k}}^{n} d P B I B C_{k(i . j-1)} I_{j}}{\sum_{i=1}^{n b} R_{i} d P B I B C_{k(i, j-1)}}+P_{\text {loadk }}
$$

where,

$$
I_{j}=\cos \theta_{k} \cdot r e\left(I_{j}\right)+\sin \theta_{k} \cdot i m\left(I_{j}\right)
$$

Type-II DG: For Type-II DG, power factor is zero. Rearranging, Eq. (6), and combining with Eq. (8), it yield as -

$$
P_{d g k}=\frac{\left|V_{k}\right| \sum_{i=1}^{n b} R_{i} \sum_{\substack{j=2 \\ j \neq k}}^{n} d P B I B C_{k(i . j-1)} I_{j}}{\sum_{i=1}^{n b} R_{i} d P B I B C_{k(i, j-1)}}+P_{\text {loadk }}
$$

where,

$$
I_{j}=\sin \theta_{k} \cdot r e\left(I_{j}\right)-\cos \theta_{k} \cdot \operatorname{im}\left(I_{j}\right)
$$

Type-III DG: For Type-III DG, power factor of DG is found by Eq. (4) while taking the sign value as +1 and computing optimal size of DG at bus k using Eq. (6-8).

Type-IV DG: For Type-IV DG, power factor of DG is found by Eq. (4) while taking the sign value as -1 and computing optimal size of DG at bus k using Eq. (6-8).

\subsection{Optimal siting of DG}

After having obtained the optimal size of DG in section (2.2), the optimum location is found, as the bus yielding minimum losses with optimal size DG. The optimal location is found by placing DG of optimal size at a time at each bus and computing losses. To avoid running load flow each time, the losses have been calculated approximately by expressing them in terms of bus current injections [16] as:

$$
P_{\text {loss }}=[R]^{T}|[B I B C] .[I]|^{2}
$$

The above formulation reduces the computational effort and the accuracy is not compromised as both exact losses and approximate losses follows same pattern. After placement of DG the bus corresponding to minimum losses is best location for placement of DG. Finally, the exact losses are computed by running the load flow. The algorithm for optimal sizing and siting can be summarized as: 
Table 1. Optimal size, optimal site, active and reactive power losses of 33-bus system

\begin{tabular}{c|c|c|c|c|c|c}
\hline $\begin{array}{c}\text { Type of } \\
\text { DG }\end{array}$ & Optimal Size of DG & $\begin{array}{c}\text { Optimal Site } \\
\text { of DG }\end{array}$ & $\begin{array}{c}\text { Active power losses after } \\
\text { DG placement }(\mathrm{kW})\end{array}$ & $\begin{array}{c}\text { Reactive power losses after } \\
\text { DG placement (kVAr) }\end{array}$ & $\begin{array}{c}\text { \% Active power } \\
\text { Loss Reduction }\end{array}$ & $\begin{array}{c}\text { \%Reactive power } \\
\text { Loss Reduction }\end{array}$ \\
\hline Type-I & $2.4908 \mathrm{MW}$ & Bus 6 & 104.051 & 74.749 & 48.568 & 44.688 \\
\hline Type-II & $1.2298 \mathrm{MVAr}$ & Bus 30 & 143.605 & 96.304 & 29.141 & 28.738 \\
\hline Type-III & 3.0139 MVA at $0.85 \mathrm{pf}$ & Bus 6 & 61.779 & 48.571 & 69.516 & 64.059 \\
\hline Type-IV & $0.8162 \mathrm{MVA}$ at $0.85 \mathrm{pf}$ & Bus 30 & 118.215 & 79.883 & 41.669 & 40.889 \\
\hline
\end{tabular}

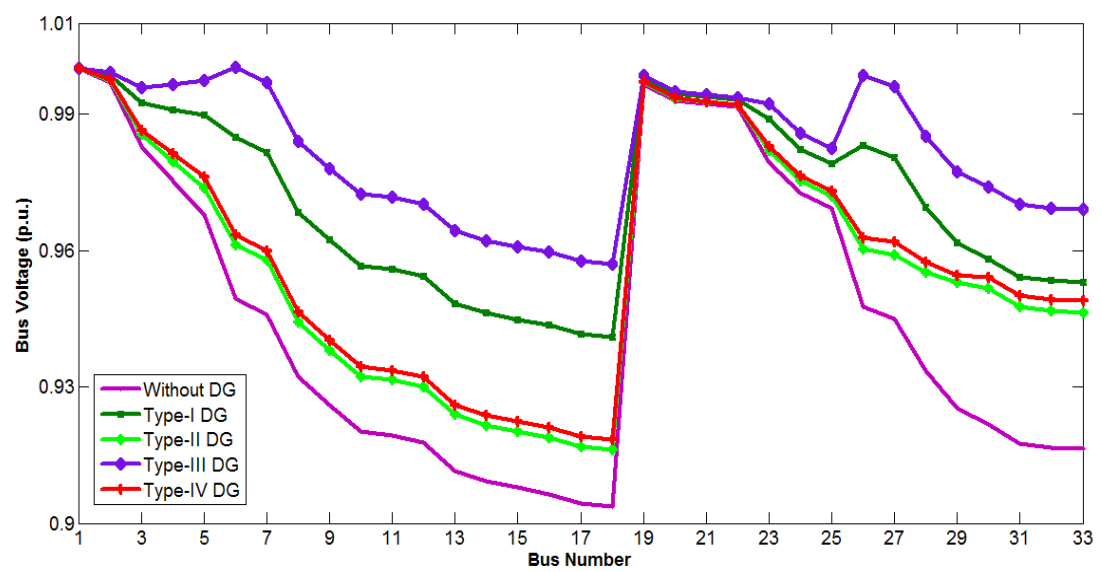

Fig. 1 Voltage variation of 33-bus system before and after placement of DG

Step 1: Read the distribution system line and bus data.

Step 2: Formulate the BIBC and BCBV matrices.

Step 3: Carryout the load flow using BIBC and BCBV matrices.

Step 4: Find the optimal size of DG for each bus except reference bus as discussed in section (2.2) while choosing suitable value of 'a' as per type of DG.

Step 5: Calculate power losses using (11) by placing DG of optimal size at each bus.

Step 6: Choose the bus corresponding to minimum losses as best location.

Step7: Run load flow to calculate exact losses by placing optimal sized DG at optimal location.

\section{Results and Discussion}

The optimal site and size of four types of DG is found to minimize the losses using analytical approach based on equivalent current injection. The analysis is carried out on 33-bus [23] and 69-bus [24] radial distribution systems. The algorithm that has been described in section (2.3) is implemented under MATLAB, R2010a.

\subsection{3-bus radial distribution system}

The 33-bus radial distribution system [23] has total load of 3.72 MW and 2.3 MVAr and it is resulting into 202.661 $\mathrm{kW}$ active power losses and 135.140 kVAr reactive power losses. The optimum allocation of Type-I, Type-II, Type-III and Type-IV DGs for 33-bus system are are summarized in Table 1.
Table 2. Summary of voltage of bus 18 after placement of DG

\begin{tabular}{c|c}
\hline Type of DG & Voltage profile of bus 18 \\
\hline Type-I & 0.9499 p.u. \\
Type-II & 0.9254 p.u. \\
Type-III & 0.9656 p.u. \\
Type-IV & 0.9280 p.u. \\
\hline
\end{tabular}

The corresponding improvement in the voltage profile of the system buses is presented in Fig. 1. It is evident from results that both maximum reductions in both active and reactive losses are obtained after placement of Type-III DG while these are minimum after placement of Type-II DG. Also Fig. 1 is evident that placement of Type-III DG results in maximum improvement in voltage profile in comparison to other types of DGs.

From base case load flow for 33-bus radial distribution system, it is found that voltage at bus 18 is minimum at 0.9038 p.u. value. The voltage at bus 18 after placement of different types of DGs is summarized in Table 2. The maximum improvement is resulted due to optimal placement of Type-III DG. Further, as shown in Fig. 1, the optimal placement of Type-III DG also results into the maximum improvement in bus voltage profile of other buses in comparison to voltage resulted with the optimal placement of other types of DGs.

\subsection{9-bus radial distribution system}

The 69-bus radial distribution system [24] has total load of 3.8 MW and 2.69 MVAr and it is resulting into active power losses of $225.005 \mathrm{~kW}$ and reactive power losses of 
Table 3. Optimal size, optimal site, active and reactive power losses of 69-bus system

\begin{tabular}{|c|c|c|c|c|c|c|}
\hline $\begin{array}{c}\text { Type of } \\
\text { DG }\end{array}$ & Optimal Size of DG & $\begin{array}{c}\text { Optimal Site } \\
\text { of DG }\end{array}$ & $\begin{array}{c}\text { Active power losses } \\
\text { after DG placement }(\mathrm{kW})\end{array}$ & $\begin{array}{c}\text { Reactive power losses after } \\
\text { DG placement (kVAr) }\end{array}$ & $\begin{array}{l}\% \text { Active power } \\
\text { Loss Reduction }\end{array}$ & $\begin{array}{c}\text { \%Reactive power } \\
\text { Loss Reduction }\end{array}$ \\
\hline Type-I & $1.8082 \mathrm{MW}$ & Bus 61 & 83.316 & 40.669 & 62.972 & 60.196 \\
\hline Type-II & 1.2918 MVAr & Bus 61 & 152.118 & 70.582 & 32.394 & 30.919 \\
\hline Type-III & $2.2223 \mathrm{MVA}$ at $0.82 \mathrm{pf}$ & Bus 61 & 23.148 & 14.406 & 89.712 & 85.900 \\
\hline Type-IV & $1.6173 \mathrm{MVA}$ at $0.82 \mathrm{pf}$ & Bus 61 & 39.106 & 22.137 & 82.620 & 78.361 \\
\hline
\end{tabular}

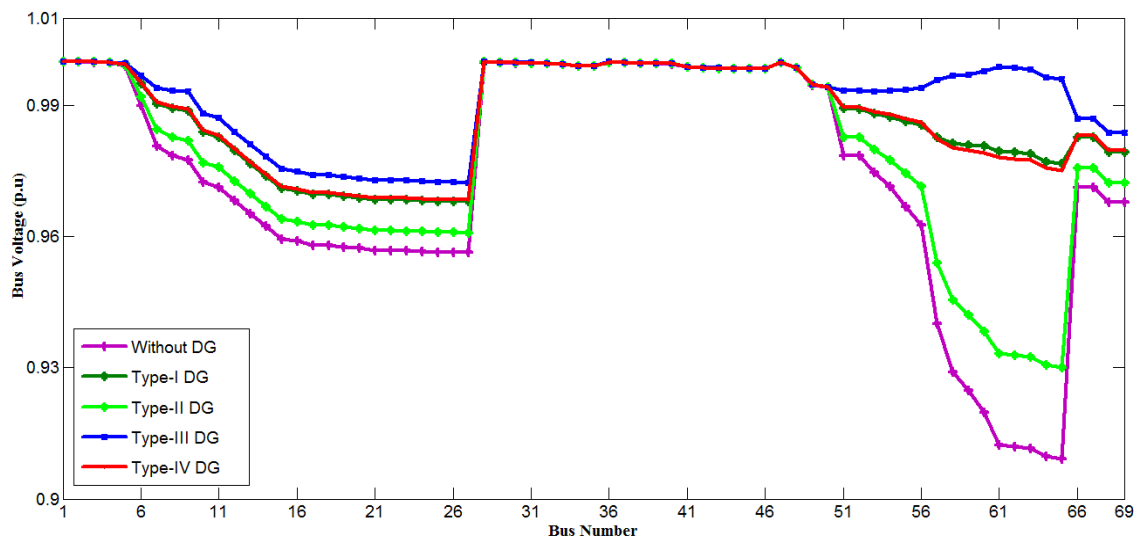

Fig. 2 Voltage variation of 69-bus system before and after placement of DG

Table 4. Summary of voltage of bus 65 after placement of DG

\begin{tabular}{c|c}
\hline Type of DG & Voltage profile of bus 65 \\
\hline Type-I & 0.9767 p.u. \\
Type-II & 0.9301 p.u. \\
Type-III & 0.9960 p.u. \\
Type-IV & 0.9751 p.u. \\
\hline
\end{tabular}

Table 5. Comparison of Type-I DG results

\begin{tabular}{c|c|c|c}
\hline Method & $\begin{array}{c}\text { Bus } \\
\text { No. }\end{array}$ & Size (MW) & $\begin{array}{c}\text { \% Active power } \\
\text { loss reduction }\end{array}$ \\
\hline Analytical [15] & 61 & 1.8078 & 62.860 \\
Analytical [16] & 61 & 1.8078 & 59.093 \\
GA [11] & 61 & 1.8100 & 62.950 \\
ABC [13] & 61 & 1.9000 & 62.970 \\
PSO [21] & 61 & 1.8078 & 62.950 \\
Proposed approach & 61 & 1.8082 & 62.972 \\
\hline
\end{tabular}

Table 6. Comparison of Type-II DG results

\begin{tabular}{c|c|c|c}
\hline Method & Bus No & $\begin{array}{c}\text { Size } \\
\text { (MVAr) }\end{array}$ & $\begin{array}{c}\text { \% Active power } \\
\text { loss reduction }\end{array}$ \\
\hline $\begin{array}{c}\text { PSO [21] } \\
\text { Proposed approach }\end{array}$ & 61 & 1.2900 & 32.400 \\
\hline
\end{tabular}

Table 7 Comparison of Type-III DG results

\begin{tabular}{c|c|c|c}
\hline Method & Bus No. & $\begin{array}{c}\text { Size } \\
\text { (MVA@pf) }\end{array}$ & $\begin{array}{c}\text { \% Active power } \\
\text { loss reduction }\end{array}$ \\
\hline Analytical [16] & 61 & $2.2219 @ 0.82$ & 89.675 \\
PSO [21] & 61 & $2.2430 @ 0.82$ & 89.690 \\
Proposed approach & 61 & $2.2223 @ 0.814$ & 89.712 \\
\hline
\end{tabular}

102.173 kVAr. The optimum allocation of Type-I, Type-II, Type-III and Type-IV DGs for this 69-bus system is summarized in Table 3.

The corresponding improvement in the voltage profile of the system buses is presented in Fig. 2. From the Table 3, it shows that the optimum allocation of Type-III DG results in maximum reduction in both active and reactive power losses. The Fig. 2 shows that optimal placement of Type-III DG causes maximum improvement in voltage profile at all the buses while Type-II DG placement yields in minimum improvement in voltage. From base case load flow for 69 bus radial distribution system, it is found that minimum voltage of 0.9092 p.u. is obtained at bus 65 . The summary of the voltage of bus 65 after placement of all types of DG is presented in Table 4.

\subsection{Comparative study}

The robustness of the proposed approach is tested on two test systems i.e. 33-bus and 69-bus radial distribution systems. The comparison of the presented results with already reported in the literature for various different types of DG's for 69-bus radial distribution system summarized in Table 5, 6 and 7 for Type-I, Type-II and Type-III DG's respectively.

\section{Conclusion}

In this paper an analytical method based on equivalent current injection is proposed to find optimal site and size of all types of DG in radial distribution system to minimize losses and thereby to improve bus voltages. The formulation 
exploits the topological features of radial distribution network. The losses with the DG placement are computed without calculating the load flow repeatedly. The effectiveness of the proposed methodology is tested on 33bus and 69-bus radial distribution systems. It is obtained that the optimal size and site of Type-I, Type-II DG, TypeIII DG and Type-IV yields in improved voltage profile and the loss reduction; however, the Type-III DG is most effective in achieving loss reduction as well as voltage profile improvement.

\section{References}

[1] M. Akorede, H. Hizam, and E. Pouresmaeil, "Distributed energy resources and benefits to the environment," Renew. Sustain. Energy Rev., vol. 14, pp. 724-734, 2010.

[2] H. Jiayi, J. Chuanwen, and X. Rong, "A review on distributed energy resources and MicroGrid," Renew. Sustain. Energy Rev., vol. 12, pp. 2472-2483, 2008.

[3] D. Q. Hung, N. Mithulananthan, R. C. Bansal, and S. Member, "Analytical Expressions for DG Allocation in Primary Distribution Networks," IEEE Trans. Energy Convers., vol. 25, no. 3, pp. 814-820, 2010.

[4] W. El-Khattam, K. Bhattacharya, Y. Hegazy, and M. M. A. Salama, "Optimal investment planning for distributed generation in a competitive electricity market," IEEE Trans. Power Syst., vol. 19, no. 3, pp. 1674-1684, 2004.

[5] G. Carpinelli, G. Celli, S. Mocci, F. Pilo, and A. Russo, "Optimisation of embedded generation sizing and siting by using a double trade-off method," IEE Proceedings-Generation, Transm. Distrib., vol. 152, no. 4, pp. 503-513, 2005.

[6] G. Celli, E. Ghiani, S. Mocci, and F. Pilo, "A multiobjective evolutionary algorithm for the sizing and siting of distributed generation," IEEE Trans. Power Syst., vol. 20, no. 2, pp. 750-757, 2005.

[7] M. Golshan and S. Arefifar, "Distributed generation, reactive sources and network-configuration planning for power and energy-loss reduction," IEE Proc.- Gener. Transm. Distrib., vol. 153, no. 2, pp. 127-136, 2006.

[8] G. Harrison, A. Piccolo, P. Siano, and A. Wallace, "Hybrid GA and OPF evaluation of network capacity for distributed generation connections," Electr. Power Syst. Res., vol. 78, pp. 392-398, 2008.

[9] M. H. Moradi and M. Abedini, "A Combination of Genetic Algorithm and Particle Swarm Optimization for Optimal DG location and Sizing in Distribution Systems," Int. J. Green Energy, vol. 9, no. 7, pp. 641660, 2012.

[10] S. G. B. Dasan and R. P. K. Devi, "Optimal Siting and Sizing of Hybrid Distributed Generation Using Fuzzy-EP," Int. J. Distrib. Energy Resour, vol. 6, no. 2, pp. 163-168, 2010.
[11] T. N. Shukla, S. P. Singh, V. Srinivasarao, and K. B. Naik, "Optimal Sizing of Distributed Generation Placed on Radial Distribution Systems," Electr. Power Components Syst., vol. 38, no. 3, pp. 260-274, Jan. 2010.

[12] R. K. Singh and S. K. Goswami, "Optimum allocation of distributed generations based on nodal pricing for profit, loss reduction, and voltage improvement including voltage rise issue," Int. J. Electr. Power Energy Syst., vol. 32, no. 6, pp. 637-644, 2010.

[13] F. S. Abu-mouti and M. E. El-Hawary, "Optimal Distributed Generation Allocation and Sizing in Distribution Systems via Artificial Bee Colony Algorithm," IEEE Trans. Power Deliv., vol. 26, no. 4, pp. 2090-2101, 2011.

[14] N. Khalesi, N. Rezaei, and M. Haghifam, "DG allocation with application of dynamic programming for loss reduction and reliability improvement," Int. J. Electr. Power Energy Syst., vol. 33, no. 2, pp. 288295, 2011.

[15] N. Acharya, P. Mahat, and N. Mithulananthan, "An analytical approach for DG allocation in primary distribution network," Electr. power energy Res., vol. 28, pp. 669-678, 2006.

[16] T. Gözel and M. H. Hocaoglu, "An analytical method for the sizing and siting of distributed generators in radial systems," Electr. Power Syst. Res., vol. 79, no. 6, pp. 912-918, Jun. 2009.

[17] D. Q. Hung and N. Mithulananthan, "Loss reduction and loadability enhancement with DG: A dual-index analytical approach," Appl. Energy, vol. 115, pp. 233241, 2014.

[18] M. A. Darfoun and M. E. El-Hawary, "Multi-objective Optimization Approach for Optimal Distributed Generation Sizing and Placement," Electr. Power Components Syst., vol. 43, no. 7, pp. 828-836, 2015.

[19] P. Kayal and K. C. Chanda, "Placement of wind and solar based DGs in distribution system for power loss minimization and voltage stability improvement," Int. J. Electr. Power Energy Syst., vol. 53, pp. 795-809, 2013.

[20] C. Yammani, S. Maheswarapu, and S. Matam, "Multiobjective Optimization for Optimal Placement and Size of DG using Shuffled Frog Leaping Algorithm," Energy Procedia, vol. 14, pp. 990-995, 2012.

[21] S. Kansal, V. Kumar, and B. Tyagi, "Optimal placement of different type of DG sources in distribution networks," Int. J. Electr. Power Energy Syst., vol. 53, no. 1, pp. 752-760, 2013.

[22] J. Teng, "A direct approach for distribution system load flow solutions," Power Deliv. IEEE Trans., vol. 18, no. 3, pp. 882-887, 2003.

[23] M. Kashem, V. Ganapathy, G. Jasmon, and M. Buhari, "A novel method for loss minimization in distribution networks," in International conference on Electric Utility Deregulation and Resturturing and Power 
Technologies 2000, 2000, pp. 251-256.

[24] M. E. Baran and F. F. Wu, "Optimal Capacitor Placement on Radial Distribution Systems," IEEE Trans. Power Deliv., vol. 4, no. 1, pp. 725-734, 1989.

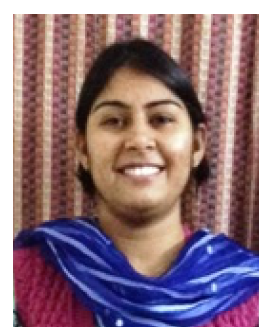

Navdeep Kaur She received B.Tech degree in electrical engineering from Punjab Technical University and M.E. in Power Systems and Electric Drives form Thapar University in 2005 and 2008 respectively. Currently She is working as Lecturer at Thapar University and pursuing $\mathrm{PhD}$. Her research interests include distribution generation and power system optimization.

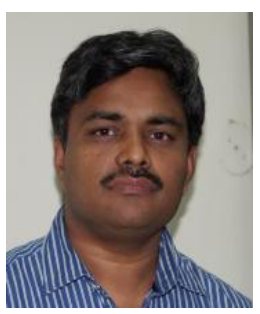

Sanjay Kumar Jain He received B.E. in Electrical Engineering from S.G.S.I.T.S, Indore in 1992, M.E. in Power System from University of Roorkee in 1995 and Ph.D. in Electrical Engineering from Indian Institute of Technology, Roorkee in 2001. Currently he is working as Associate Professor at Thapar University Patiala. His research interests are induction generators and power system optimization.

\section{Appendix A}

The total power loss is given by:

$$
P_{\text {loss }}=[R]^{T}\left([B I B C]\left[\frac{P \cos \theta+Q \sin \theta}{|V|}\right]\right)^{2}+[R]^{T}\left([B I B C]\left[\frac{P \sin \theta-Q \cos \theta}{|V|}\right]\right)^{2}
$$

The Eq. (A-1) can be re-written into expanded form as -

$$
P_{\text {loss }}=\sum_{i=1}^{n b} R_{i}\left(\sum_{j=2}^{n} B I B C_{i, j-1}\left[\frac{P_{j} \cos \theta_{j}+Q_{j} \sin \theta_{j}}{\left|V_{j}\right|}\right]\right)^{2}+\sum_{i=1}^{n b} R_{i}\left(\sum_{j=2}^{n} B I B C_{i, j-1}\left[\frac{P_{j} \cos \theta_{j}-Q_{j} \sin \theta_{j}}{\left|V_{j}\right|}\right]\right)^{2}
$$

As $Q_{j}=\mathrm{a} P_{j}$, so equation (A-2) becomes:

$$
P_{\text {loss }}=\sum_{i=1}^{n b} R_{i}\left(\sum_{j=2}^{n} B I B C_{i, j-1}\left[\frac{P_{j} \cos \theta_{j}+a P_{j} \sin \theta_{j}}{\left|V_{j}\right|}\right]\right)^{2}+\sum_{i=1}^{n b} R_{i}\left(\sum_{j=2}^{n} B I B C_{i, j-1}\left[\frac{P_{j} \cos \theta_{j}-a P_{j} \sin \theta_{j}}{\left|V_{j}\right|}\right]\right)^{2}
$$

The objective to find the optimum size of DG at a bus is calculated by making the power loss to real power injection sensitivity factor as zero i.e. $\frac{\partial P_{l o s s}}{\partial P_{k}}=0$.

$$
\begin{gathered}
\frac{\partial \text { Ploss }}{\partial P_{k}}=\sum_{i=1}^{n b} 2 R_{i}\left[\sum_{j=2}^{n} B I B C_{i, j-1}\left(\frac{P_{j} \cos \theta_{j}+a P_{j} \sin \theta_{j}}{\left|V_{j}\right|}\right) B I B C_{i, k-1}\left(\frac{\cos \theta_{k}+a \sin \theta_{k}}{\left|V_{k}\right|}\right)\right]+ \\
\sum_{i=1}^{n b} 2 R_{i}\left[\sum_{j=2}^{n} B I B C_{i, j-1}\left(\frac{P_{j} \sin \theta_{j}-a P_{j} \cos \theta_{j}}{\left|V_{j}\right|}\right) B I B C_{i, k-1}\left(\frac{\sin \theta_{k}-a \cos \theta_{k}}{\left|V_{k}\right|}\right)\right] \\
\frac{\partial \text { Ploss }}{\partial P_{k}}=\sum_{i=1}^{n b} 2 R_{i}\left[\sum_{j=2}^{n} B I B C_{i, j-1} r e\left(I_{j}\right) B I B C_{i, k-1}\left(\frac{\cos \theta_{k}+a \sin \theta_{k}}{\left|V_{k}\right|}\right)\right]+\sum_{i=1}^{n b} 2 R_{i}\left[\sum_{j=2}^{n} B I B C_{i, j-1} i m\left(I_{j}\right) B I B C_{i, k-1}\left(\frac{\sin \theta_{k}-a \cos \theta_{k}}{\left|V_{k}\right|}\right)\right]
\end{gathered}
$$

here

$$
r e\left(I_{j}\right)=\frac{P_{j} \cos \theta_{j}+a P_{j} \sin \theta_{j}}{\left|V_{j}\right|} \text { and } \operatorname{im}\left(I_{j}\right)=\frac{P_{j} \sin \theta_{j}-a P_{j} \cos \theta_{j}}{\left|V_{j}\right|}
$$


If the $\mathrm{k}^{\text {th }}$ bus is not connected the $\mathrm{j}^{\text {th }}$ branch then the elements of $\mathrm{BIBC}$ matrix is zero $(\mathrm{BIBC}(\mathrm{j}, \mathrm{k}-1)=0)$ and the derivative of the corresponding element is equated to zero $\left(\frac{\partial P_{\text {loss }}}{\partial P_{k}}=0\right)$. Accordingly, the derivative of the total power losses per $\mathrm{k}^{\text {th }}$ bus injected real power gives the sensitivity factor and can be expressed as:

$$
\frac{\partial \text { Ploss }}{\partial P_{k}}=\sum_{i=1}^{n b} 2 R_{i} \sum_{j=2}^{n} d B I B C_{i, j-1}\left[r e\left(I_{j}\right)\left(\frac{\cos \theta_{k}+a \sin \theta_{k}}{\left|V_{k}\right|}\right)+i m\left(I_{j}\right)\left(\frac{\sin \theta_{k}-a \cos \theta_{k}}{\left|V_{k}\right|}\right)\right]
$$

Expanding Eq. (A-6)

$$
\begin{aligned}
& \frac{\partial P_{\text {loss }}}{\partial P_{k}}=\sum_{i=1}^{n b} 2 R_{i} \sum_{\substack{j=2 \\
j \neq k}}^{n} d B I B C_{i, j-1}\left[r e\left(I_{j}\right)\left(\frac{\cos \theta_{k}+a \sin \theta_{k}}{\left|V_{k}\right|}\right)+i m\left(I_{j}\right)\left(\frac{\sin \theta_{k}-a \cos \theta_{k}}{\left|V_{k}\right|}\right)\right]+ \\
& \sum_{i=1}^{n b} 2 R_{i} d B I B C_{i, k-1}\left[r e\left(I_{k}\right)\left(\frac{\cos \theta_{k}+a \sin \theta_{k}}{\left|V_{k}\right|}\right)+\operatorname{im}\left(I_{k}\right)\left(\frac{\sin \theta_{k}-a \cos \theta_{k}}{\left|V_{k}\right|}\right)\right]
\end{aligned}
$$

using the value of $r e\left(I_{k}\right)$ and $i m\left(I_{k}\right)$ Eq. (A-7) becomes:

$$
\begin{aligned}
& \frac{\partial P_{\text {loss }}}{\partial P_{k}}=\sum_{i=1}^{n b} 2 R_{i} \sum_{\substack{j=2 \\
j \neq k}}^{n} d B I B C_{i, j-1}\left[r e\left(I_{j}\right)\left(\frac{\cos \theta_{k}+a \sin \theta_{k}}{\left|V_{k}\right|}\right)+i m\left(I_{j}\right)\left(\frac{\sin \theta_{k}-a \cos \theta_{k}}{\left|V_{k}\right|}\right)\right]+ \\
& \sum_{i=1}^{n b} 2 R_{i} d B I B C_{i, k-1}\left[\left(\frac{P_{k} \cos \theta_{k}+a P_{k} \sin \theta_{k}}{\left|V_{k}\right|}\right)\left(\frac{\cos \theta_{k}+a \sin \theta_{k}}{\left|V_{k}\right|}\right)+\left(\frac{P_{k} \sin \theta_{k}-a P_{k} \cos \theta_{k}}{\left|V_{k}\right|}\right)\left(\frac{\sin \theta_{k}-a \cos \theta_{k}}{\left|V_{k}\right|}\right)\right]
\end{aligned}
$$

on solving Eq. (A-8), it becomes:

$$
\begin{aligned}
& \frac{\partial P_{\text {loss }}}{\partial P_{k}}=\sum_{i=1}^{n b} 2 R_{i} \sum_{\substack{j=2 \\
j \neq k}}^{n} d B I B C_{i, j-1}\left[r e\left(I_{j}\right)\left(\frac{\cos \theta_{k}+a \sin \theta_{k}}{\left|V_{k}\right|}\right)+i m\left(I_{j}\right)\left(\frac{\sin \theta_{k}-a \cos \theta_{k}}{\left|V_{k}\right|}\right)\right]+\sum_{i=1}^{n b} 2 R_{i} d B I B C_{i, k-1} \frac{P_{k}\left(1+a^{2}\right)}{\left|V_{k}\right|^{2}} \\
& \text { As } \frac{\partial P_{\text {loss }}}{\partial P_{k}}=0 \text {; so } \\
& 0=\sum_{i=1}^{n b} 2 R_{i} \sum_{\substack{j=2 \\
j \neq i}}^{n} d B I B C_{i, j-1}\left[r e\left(I_{k}\right)\left(\frac{\cos \theta_{k}+a \sin \theta_{k}}{\left|V_{k}\right|}\right)+i m\left(I_{k}\right)\left(\frac{\sin \theta_{k}-a \cos \theta_{k}}{\left|V_{k}\right|}\right)\right]+\sum_{i=1}^{n b} 2 R_{i} d B I B C_{i, k-1} \frac{P_{k}\left(1+a^{2}\right)}{\left|V_{k}\right|^{2}}
\end{aligned}
$$

by solving this equation $P_{k}$ becomes:

$$
P_{k}=\frac{-\left|V_{k}\right| \sum_{i=1}^{n b} R_{i} \sum_{\substack{j=2 \\ j \neq i}}^{n} d B I B C_{i, j-1}\left[r e\left(I_{j}\right)\left(\cos \theta_{k}+a \sin \theta_{k}\right)+i m\left(I_{j}\right)\left(\sin \theta_{k}-a \cos \theta_{k}\right)\right]}{\left(1+a^{2}\right) \sum_{i=1}^{n b} R_{i} d B I B C_{i, k-1}}
$$

